\title{
QUANDO O MEDO E O PERIGO SE CONECTAM: O USO DA DEEPWEB E A (IN)SEGURANÇA DOS CIDADÃOS.
}

\author{
Renata Almeida da Costa ${ }^{1}$ \\ Karen Lucia Bressane Rubim ${ }^{2}$
}

\begin{abstract}
RESUMO
A pesquisa aborda a sociedade da informação para contextualizar a internet como fomento da globalização e mutação nas relações sociais. Exterioriza o surgimento do medo, quando se trata de acesso à ciberespaço sem indexação de dados, chamado de "DeepWeb". Ainda, busca verificar eventuais consequências desse medo na ressignificação de perigo quando do acesso a "DeepWeb" e a (des) necessidade de tutela penal. O trabalho tem como metodologia referencial bibliográfico e análise de caso, utilizando como marco teórico o aparato sociológico proposto por Anthony Giddens quanto à modernidade, sua transição e consequências.
\end{abstract}

Palavras-chave: sociedade da informação; medo; perigo; DeepWeb; estigma.

\section{WHEN FEAR AND DANGER CONNECT: THE USE OF DEEPWEB AND THE INSECURITY OF CITIZENS.}

\begin{abstract}
The research addresses the information society to contextualize the internet as a means of promoting globalization and mutation in social relations. It expresses the emergence of fear, when it comes to accessing cyberspace without data indexing, called "DeepWeb". Still, it seeks to verify possible consequences of this fear in the redefinition of danger when accessing "DeepWeb" and the (un) need for criminal protection. The work has as bibliographic referential methodology and case analysis, using as a theoretical framework the sociological apparatus proposed by Anthony Giddens regarding modernity, its transition and consequences.
\end{abstract}

Keywords: information society; fear; danger; DeepWeb; stigma.

\footnotetext{
${ }^{1}$ Doutora em Direito pela UNISINOS (2010), Mestre em Ciências Criminais pela Pontifícia Universidade Católica do Rio Grande do Sul (2002) e graduada em Direito pela Universidade de Passo Fundo (1998). Realizou estágio Pós-Doutoral no Instituto Internacional de Sociologia Jurídica de Oñati (2015). É professora e coordenadora do Programa de Pós-Graduação em Direito (Mestrado e Doutorado) da Universidade La Salle e professora do curso de Graduação em Direito. Foi professora da Faculdade de Direito da Universidade Anhembi Morumbi (2015), do Uniritter (2011 a 2015) e da Universidade de Passo Fundo (2000 a 2012) e pesquisadora visitante da Universidade de Reading (Inglaterra), onde realizou doutorado-sanduíche. Tem experiência na área de Direito, com ênfase em Direito Penal e Criminologia, atuando principalmente nos seguintes temas: criminalildade organizada, controle social, sociedade, terrorismo, cultura do medo e urbanização. É integrante do Cadastro Nacional e Internacional de avaliadores do CONPEDI - Conselho Nacional de Pesquisa e PósGraduação em Direito. É presidenta da ABRASD - Associação Brasileira dos Pesquisadores em Sociologia do Direito (gestão 2020/2021). https://orcid.org/0000-0001-9744-4668. E-mail: renata.costa@ unilasalle.edu.br.

${ }^{2}$ Graduada em Direito pela PUCRS em 2007. Especialista em Ciências Penais pela PUCRS em 2010. Especializanda em Direito Digital pela Uniritter. Mestranda em Direito e Sociedade pela Universidade LaSalle. https://orcid.org/0000-0001-8276-0879. E-mail: karen.rubim@gmail.com.
} 


\section{INTRODUÇÃO}

O presente trabalho, tendo por marco teórico o arcabouço sociológico proposto por Anthony Giddens e por meio de referencial bibliográfico e análise de caso, aborda o surgimento da sociedade da informação na concepção moderna já operada a transição da vida sólida para experiência líquida quanto à organização social. Verificado o momento histórico, o trabalho tenta explicitar as consequências do surgimento do cenário informacional quanto às relações sociais e o despreparo das instituições estatais e políticas para mitigar a precarização do indivíduo nessa realidade global.

Evoluindo na sociedade da informação, se pontua a extrospeção da interação social pelas mãos da globalização, abrindo o caminho para o novo cenário de desenvolvimento das ditas relações: o ciberespaço e, porque nesse âmbito os direitos de proteção constitucional da liberdade de expressão e privacidade entram em colisão em nome de um exibicionismo.

Verificada a presença do Ciberespaço como novo palco de interação social, a pesquisa indica a Internet como mola propulsora da extimidade digital e concentra seus argumentos na utilização de ambiente virtual com indexação de dados e a internet profunda e estigma atrelado aos seus usuários em rechaço à extimidade.

Feito todo o apanhado proposto, o trabalho se vale do arcabouço sociológico utilizado também por Anthony Giddens para entender o caso ocorrido em Suzano-SP e o papel da utilização da DeepWeb para consultoria do crime e a (des) necessidade de tutela penal do ambiente sem indexação de dados.

\section{O SURGIMENTO DA SOCIEDADE DA INFORMAÇÃO}

O cenário informacional resulta também da interação e dinâmica existente entre os diversos sistemas sociais que nos permeiam e que por nossas relações se ramificam cada vez mais. Para Anthony Giddens (2002, p. 170), "processos de mudança engendrados pela modernidade estão intrinsicamente ligados a influências globalizantes, e a simples sensação de ser presa das maciças ondas de transformação é perturbadora".

Não se pretende atrelar ao surgimento da sociedade da informação somente às mazelas da globalização, inclusive pelas mãos da Internet, mas também catalogar de que 
forma as relações sociais precarizam o indivíduo, em atenção ao despreparo coletivo para recepcionar a mudança do paradigma.

\subsection{A Modernidade e a superação do caráter estático da sociedade}

Pode-se, sem dúvidas aparentes, creditar ao período moderno, no qual ainda estamos inseridos no entender de Giddens ${ }^{3}$, mesmo que de forma descontinuada, a superação do caráter estático do sistema social.

Em seu entender (GIDDENS, 1991, p. 14), “os modos de vida produzidos pela modernidade nos desvencilharam de todos os tipos tradicionais de ordem social, de uma maneira que não tem precedentes". Imbuídos de uma velocidade e abrangência distintas da experiência tradicional, a estrutura social moderna implica num caráter volátil das relações interpessoais cuja conexão deixa de ser apenas local para atingir patamar global.

Esse paradoxo é explicado por Bauman pelo "grau de abertura" de uma determinada sociedade, pois quanto mais aberta mais conectada e, portanto, sem fronteiras aparentes, tanto geográficas quanto sociais.

Ocorre que, antes que se proponha digressão sobre outras nuances da estrutura social na modernidade, necessário é entender do que se trata o conceito de sociedade. Para tanto, o presente trabalho se valerá da visão sociológica de Anthony Giddens (2009, p. 192-194): “Em suma, as "sociedades" são, pois, sistemas sociais que se destacam em baixo-relevo de um fundo constituído por toda uma série de relações sistêmicas, nas quais elas estão inseridas.”.

Pode-se entender que o conceito de sociedade não é superado pela era vivida e sim agregado pelos sistemas em que se insere e com os quais se conecta e interage. Nesse sentido, assevera De Giorgi (1998, p. 153):

(...) a sociedade aparece para si mesma como o resultado de si própria. Se assim não fosse, ela não poderia perceber-se como um sistema que opera somente no presente. Essa contínua repetição da produção de indeterminação obriga-nos a observar a sociedade como um sistema que se observa, isto é, como um sistema que se diferencia e, ainda, como um sistema que não pode operar fora de si mesmo.

\footnotetext{
${ }^{3}$ Como deveríamos identificar as descontinuidades que separam as instituições sociais modernas das ordens sociais tradicionais? Diversas características estão envolvidas. Uma delas é o ritmo de mudança nítido que a era da modernidade põe em movimento. As civilizações tradicionais podem ter sido consideravelmente mais dinâmicas que outros sistemas pré-modernos, mas a rapidez da mudança em condições de modernidade é extrema. Se isto é talvez mais óbvio no que toca à tecnologia, permeia também todas as outras esferas. Uma segunda descontinuidade é o escopo da mudança. Conforme diferentes áreas do globo são postas em interconexão, ondas de transformação social penetram através de virtualmente toda a superfície da terra. GIDDENS, Anthony. As consequências da Modernidade. tradução Raul Fiker. São Paulo: Editora Unesp, 1991. p. 16.
} 
No contexto moderno, para Leonel Severo, Germano Schwartz e Jean Clam (2013, p. 13), "a forma característica da sociedade moderna é a diferenciação: separam-se indissoluvelmente as esferas do poder, do saber, da lei, da religião, do prazer, implicando a necessidade de legitimação constante de suas áreas de atuação". Posicionam que "neste tipo de sociedade existe uma grande indeterminação, tudo está em aberto, a discutir" e "tem de enfrentar assim a complexidade produzida pela possibilidade de se tomar decisões sempre diferentes".

Inegável que a complexidade da sociedade decorre também de seu processo de globalização, o que Bauman vai dizer se tratar de globalização negativa ${ }^{4}$ na sociedade moderna, e que Hall (2005, p. 14), ao pontuar as sociedades modernas, as conceitua como "sociedades de mudança constante, rápida e permanente".

\subsubsection{A velocidade e a expansão das relações sociais}

Como bem pontuou Castells (2000, p. 39), "uma revolução tecnológica concentrada nas tecnologias da informação começou a remodelar a base material da sociedade em ritmo acelerado". Sociedade essa, tratada em condições da modernidade, vem se pautando pela alta velocidade de suas relações, abalroando de vez as fronteiras geográficas e locais das totalidades sociais.

O minar das fronteiras possibilita a expansão da intersecção social, onde “o desenvolvimento das instituições sociais modernas e sua difusão em escala mundial criaram oportunidades bem maiores para os seres humanos gozarem de uma existência segura e gratificante que qualquer tipo de sistema pré-moderno" (GIDDENS, 2013, p. 17).

Se na concepção tradicional, as relações não extrapolavam os limites locais (bairros e cidades) por condição de sua estrutura, a experiência moderna traz aos seus sistemas sociais e intersociais uma forma global de interação possibilitando uma gama de prognósticos para um futuro incerto e imprevisível.

À experiência moderna se pode atribuir a vertente informacional da sociedade, cenário onde o indivíduo se ressignifica a partir de sua identidade, entendida por Castells (2000, p. 57-58) como "processo pelo qual um ator social se reconhece e constrói significado principalmente com base em determinado atributo cultural", o que denota um crescente na

\footnotetext{
${ }^{4} \mathrm{O}$ atributo da abertura, antes um produto precioso, ainda que frágil, da corajosa, mas estafante autoafirmação, é associado, hoje, principalmente a um destino irresistível -, aos efeitos não planejados e imprevistos da "globalização negativa" -, ou seja, uma globalização seletiva do comércio e capital, da vigilância e da informação, da violência e das armas, do crime e do terrorismo. BAUMAN, Zygmunt. Tempos Líquidos. tradução Carlos Alberto Medeiros. Rio de Janeiro: Zahar, 2007. p. 13.
} 
relação entre o ser, sua identidade e âmbito social, local que agora chamaremos de Sociedade da Informação onde " as novas tecnologias de informação estão integrando o mundo em redes globais de instrumentalidade". (CASTELLS, 2000, p. 57)

Diante dessa ausência de fronteiras e necessidade de se estar seguro de alguma ameaça decorrente do caráter incerto desse futuro informacional, a busca do ser nesse contexto ramificado é fortalecer e preservar a identidade cultural da comunidade que está inserido, pois os efeitos da revolução tecnológica e o viver e se desenvolver na sociedade volátil e em processo de globalização tirou do indivíduo seu local de pertencimento perene.

\subsubsection{A precarização do ser humano na sociedade da informação}

$\mathrm{Na}$ contramão de um utópico ideal pacífico que deveria imperar na experiência moderna, o que se verifica é a precarização do indivíduo, a perda de sua identidade cultural pela negação da diferença e a experimentação de sensação de insegurança pelo grau de abertura da sociedade sem a ingerência da política por meio do Estado-nação.

Essa insegurança se alimenta de um proceder extremado para reestabelecer a segurança perdida, onde o progresso, que deveria ser a mola propulsora da manutenção da autoafirmação da sociedade aberta, "evoca uma insônia cheia de pesadelos de ser deixado para trás - de perder o trem ou cair da janela de um veículo em rápida aceleração". (BAUMAN, 2007, p. 17).

E envolto à transição da vida estática para a vida em constante movimento e em aceleração está o indivíduo que perdeu sua identidade já que não pertence a essa ou aquela comunidade e sim à visão global do mundo moderno. Não se pretende dizer que a perda da identidade justifica posturas totalitárias pelas mãos da religião ou outra vertente ideológica, mas sim que de fato elas surgiram diante da incapacidade das instituições políticas e estatais de caráter local para contemporizar problemas nitidamente globais (BAUMAN, 2009, p. 2829).

Diz-se de caráter local, pois mesmo que não previsto no projeto da modernidade, pela transição houve a decomposição ${ }^{5}$ do Estado social, onde as instituições políticas ainda estão organizadas sob a égide da modernidade sólida já que não possuem fôlego e preparo para a realidade global.

${ }^{5}$ (...) essa exclusão irrevogável é a consequência direta, embora imprevista, da decomposição do Estado social, que hoje se assemelha a uma rede de poderes constituídos, ou melhor, a um ideal, a um projeto abstrato. O declínio e o colapso do Estado social anunciam definitivamente que as oportunidades de redenção irão desaparecer. BAUMAN, Zygmunt. Confiança e medo na cidade. tradução Eliana Aguiar. Rio de Janeiro: Zahar, 2009. p. 23. 
Assim, ao invés de reconhecimento do multiculturalismo decorrente de um mundo global e sem fronteiras, se tem a polarização, a mixofobia e a mixofilia. Nesse sentido, importante parafrasear a estrutura trazida por Giddens (1991, p. 31) quanto ao desencaixe dos sistemas sociais, o que sobremaneira sensibiliza o indivíduo na sociedade moderna. Em seu entender, desencaixe remonta "o deslocamento das relações sociais de contextos locais de interação e sua reestruturação através de extensões indefinidas de tempo-espaço".

Percebe-se que nessa transição, o sujeito deixa de ter relação com a cidade que habita já que não se sente conectado com qualquer laço comunitário, os quais, diga-se desde, já foram abruptamente rompidos pelo vórtice global. Mais, se um dia o sujeito moderno foi caracterizado pelo racionalismo exacerbado, agora se vê diante de uma realidade multidimensional que lhe retira a condição ver algo além de sua precarização, desconfiança, abandono e medo.

\subsection{A extrospeção da sociedade pelas mãos da globalização}

Considerando a experiência moderna já no viés líquido e os primeiros efeitos globalizantes, se pode dizer com alguma segurança que a interação social já não é mais introspectiva eis que as barreiras que condicionavam o caráter local da informação foram dissolvidas pela revolução tecnológica.

Para Bauman, "a ideia de sociedade aberta representa originalmente a autodeterminação de uma sociedade livre, orgulhosa de sua abertura, agora traz à maioria das mentes a experiência terrificante de populações heterônomas". (BAUMAN, 2008, p. 127)

Para Giddens (1991, p. 75), “a modernidade é inerentemente globalizante”, onde a "sociedade não é um sistema limitado" e a globalização é identificada como um "processo de alongamento, na medida em que as modalidades der conexão entre diferentes regiões ou contextos sociais se enredaram através da superfície da terra como um todo". Ainda, assevera o distanciamento de dois vetores: tempo e espaço.

E isso é pacífico e facilmente verificável, pois no cenário da informação e tecnologia a comunicação e variadas transações podem ocorrer sem limitação de espaço e tempo, onde esses vetores já não caminham em comunhão, mas não desaparecem da experiência moderna.

Diante do processo de globalização e grau de abertura da sociedade da informação é possível lhe atribuir o predicado da extrospecção, inclusive diante dos novos cenários onde as relações humanas podem se desenvolver. 


\subsubsection{A ampliação das fronteiras sociais e medo do indivíduo}

Em exaustão, a experiência moderna em sua fase líquida dissolveu as barreiras geográficas, locais e de comunicação da sociedade, fazendo surgir um cenário informacional que propiciou inclusive a comercialização da internet ${ }^{6}$ e, por consequência, a expansão das relações sociais em razão também do distanciamento dos vetores tempo e espaço.

À margem das mazelas advindas da modernidade, fato é que a sociedade da informação propiciou a ampliação das formas de interação social, potencializando seu grau de abertura. Grau esse que determina também o grau de complexidade e incertezas da mesma sociedade, distanciando esse conceito de uma necessária segurança.

Sociedade essa que "produz complexidade, ou seja, excesso de possibilidades, pois a sociedade se faz instável por si mesma e, a um só tempo, produz contingência, visto que no presente tudo pode ser diverso" (DE GIORGI, 1998, p. 153).

Complementa que, "a sociedade contemporânea expandiu a tal ponto as possibilidades da comunicação que que pode representar-se a si mesma como um sistema compreensivo da comunicação social" (DE GIORGI, 1998, p. 169) e que carrega em si, diante da gama de prognósticos para o futuro, o "risco imanente que não pode se constituir objeto de prevenção, como habitualmente se crê" (DE GIORGI, 1998, p. 182) sendo que "a sociedade não pode impedir as potencialidades imanentes à sua estrutura" (DE GIORGI, 1998, p. 182).

Imprescindível dizer que, no entender de Rafaelle de Giorgi (1998, p. 182), o risco é uma condição estrutural da auto-repetição:

É claro que este risco está ligado à incerteza que caracteriza o futuro dos indivíduos, quer se trate daqueles que observam a si mesmos, ou de um observador externo, como um sistema social. Esta incerteza torna precários os cálculos e priva de todo o fundamento de plausibilidade as previsões. A incerteza pode transformar-se em medo ou carregar-se de agressividade: o risco desta incerteza está no fato de que pode transformar-se em violência contra si mesmo, ou contra os outros.

Nesse sentido são as pertinentes considerações de Renata Almeida da Costa (2004, p. 33), onde "é de domínio doutrinário que a sociedade caracterizada pela pós-modernidade é

\footnotetext{
${ }^{6}$ O ARPANET, projeto que se consolidou na década de 1960 no período pós-guerra (WENDT, 2019, p. 59), logo passou a ser sincronizado em outros nichos. Somente em 1980 esse algoritmo passou a ser denominado de Internet, e na década de 1990, um novo salto tecnológico permitiu a difusão da Internet na sociedade em geral: a criação de um novo aplicativo, a teia mundial (world wide web -WWW) (CASTELS, 2000 , p. 88). Teia essa que organizava o teor dos sítios da Internet por informação, e não por localização, oferecendo aos usuários um sistema fácil de pesquisa para procurar as informações desejadas. (CASTELS, 2000, p. 88).
} 
marcada pela indeterminação e pela instabilidade, geradas pela falta de segurança e pela possibilidade premente do dano em face do risco inerente às ações”.

Similitude conceitual reside no entendimento sociológico do risco na sociedade contemporânea, já que essa "tem como característica maior o risco e a incerteza, no que se diferencia da sociedade moderna, que primava pelo perigo e pela certeza. " (SCHWARTZ, 2004, p. 39). A experiência tradicional desconhecia a palavra risco "porque não necessitavam de uma designação para algo que não ocorria", contando apenas com os "atores que proporcionavam o perigo e que eram conhecidos e facilmente identificáveis, o que já elidia uma possível complexidade e incerteza.

Em Ulrich Beck (2010, p. 39):

\begin{abstract}
Riscos não se esgotam, contudo, em efeitos e danos já ocorridos. Neles, exprime-se sobretudo um componente futuro. Este baseia-se em parte na extensão futura dos danos atualmente previsíveis e em parte numa perda geral de confiança ou num suposto amplificador do risco. Riscos têm, portanto, fundamentalmente que ver com antecipação, com destruições que ainda não ocorreram, mas que são imanentes, e que, justamente nesse sentido, já são reais.
\end{abstract}

Para Giddens (1991, p. 41), a noção de risco "se originou com a compreensão de que resultados inesperados podem ser uma consequência de nossas próprias atividades ou decisões, ao invés de exprimirem resultados ocultos da natureza".

Avançando, Bauman (2008, p. 9) infere que "o medo é um sentimento conhecido de toda a criatura viva" e que diante desse mundo de incertezas e riscos se pode verificar um outro tipo de medo, tido como "medo derivado" visto como uma "estrutura mental que pode ser mais bem descrita como o sentimento de ser suscetível ao perigo; uma sensação de insegurança (o mundo está cheio de perigos que podem se abater sobre nós a qualquer momento).".

Nesse cenário:

Uma pessoa que tenha interiorizado uma visão de mundo que inclua a insegurança e a vulnerabilidade recorrerá rotineiramente, mesmo na ausência de ameaça genuína, às reações adequadas a um encontro imediato com o perigo; $p$ "medo derivado" adquire a capacidade de autopropulsão. (...) o medo derivado é facilmente desacoplado dos perigos que o causam. (BAUMAN, 2008, p. 10)

Complementa que, "no ambiente líquido-moderno, contudo, a luta contra os medos se tornou tarefa para a vida inteira, enquanto os perigos que os deflagram passaram a ser 
considerados companhias permanentes e indissociáveis da vida humana". (BAUMAN, 2008, p. 15).

Conforme Giddens (1991, p. 44) alude, a noção de risco está para a confiança, pois essa pressupõe a consciência das circunstâncias do risco e "está basicamente vinculada, não ao risco, mas à contingência". Para ele, "perigo e risco estão intimamente relacionado, mas não são a mesma coisa".

Nesse sentido, discorre:

O que o risco pressupõe é precisamente o perigo (não necessariamente a consciência do perigo). Uma pessoa que arrisca algo corteja o perigo, onde o perigo é compreendido como uma ameaça aos resultados desejados. Qualquer um que assume um risco calculado está consciente da ameaça ou ameaças que uma linha de ação específica pode pôr em jogo. (GIDDENS, 1991, p. 44)

Assim, pode-se ponderar que a confiança tem a função de minimizar os perigos inerentes à determinadas ações e que, inclusive a não ação, que já encerra juízo de valor também comporta sua parcela de riscos e perigos, mas se são calculados e previsíveis, não se detém com certeza essa informação.

\subsubsection{O surgimento de novos cenários de interação e o exibicionismo das relações}

A sociedade da informação ${ }^{7}$ é responsável pela disseminação, inclusive, comercial da Internet $^{8}$, ferramenta antes de exclusividade militar e governamental.

Esse é o cenário que o presente trabalho abordará: o ciberespaço ${ }^{9}$ e se o exibicionismo presente na interação social, agora virtual e digital decorre do elemento humano ou da própria estrutura do ciberespaço como forma de manipulação da informação.

\footnotetext{
${ }^{7}$ Sociedade da informação é consequência da sociedade pós-industrial e, possui algumas características, assim resumidas: (a0 a informação é um produto e o saber um fator econômico; (b) a distância e o tempo entre a informação e o destinatário não tem mais sentido, ou seja, a perda da noção de tempo e espaço, ou seja, uma acronia e uma atopia; (c) há valor agregado à informação, revolucionado pelas tecnologias da informação e comunicação que, além de revolucionar o mercado, criando novos serviços, empresas empregos, transformaram o mundo em uma ladeia global; (d) o ciclo informativo se transformou, pois além do usuário se tornar produtor (de conhecimento), há para isso um baixo custo, mesmo quando se trata de armazenamento de grande volume de dados, e; (e) o processamento, recuperação e acesso às informações se tornou mais célere, seguro e eficaz, possibilitando o monitoramento e avaliação dos dados/informações. KRETSCHMANN, Ẩngela, WENDT, Emerson. Tecnologia da Informação \& Direito. Porto Alegre: Livraria do Advogado, 2018. p. 12.

${ }^{8}$ Além das várias características da Internet, que solidificou a chamada "sociedade da informação", como a massificação das informações, o acesso a sistemas e dados, multidiversidade de assuntos (...) a autodesenvolvimento é a principal (característica). KRETSCHMANN, Ângela, WENDT, Emerson. Tecnologia da Informação \& Direito. Porto Alegre: Livraria do Advogado, 2018. p. 39.

${ }^{9}$ Termo criado e utilizado pela primeira vez pelo escritor américo-canadense Willian Gibson em sua obra Neuromancer para se referir a um espaço virtual que era composto por cada computador e usuário conectado em uma rede mundial. Segundo William Gibson, ciberespaço é o conjunto de rede de computadores na quais todo o tipo de informação é circulada. Gibson define ciberespaço como um espaço existente no mundo da comunicação. Nesse meio, para que se possa construir uma fonte de relacionamento, não é necessária a presença física de um humano.
} 
Antes que se verifique o motivo do exibicionismo, importante dizer que tal assertiva está intimamente ligada à liberdade do indivíduo em se expressar e se fazer presente em ambiente digital. Liberdade essa caracterizadora da sociedade contemporânea e da informação, o que no entender de Renata Almeida da Costa (2004, p. 09) "é fator característico da sociedade moderna" onde a liberdade individual é "expoente deste tipo de sociedade".

Quarenta anos antes de estar em nosso texto constitucional, a liberdade de expressão vem estampada no artigo XIX da Declaração Universal do Direitos Humanos ${ }^{10}$. Na Constituição Federal de 1988, tal liberdade vem estampada como direito fundamental presente no artigo $1 .^{\circ}$ inciso $\mathrm{V}$ pelo pluralismo político; no artigo $5 .^{\circ}$ pelos incisos IV, VIII e IX e, artigo 220, § 2. .

A liberdade de expressão agora pode ser manifestada em plataformas digitais, redes sociais, páginas da Internet e aplicações variadas utilizadas também como meio de comunicação, como por exemplo o Facebook, Instagram, Snapchat, Twitter; Tinder etc.

Ocorre que todas as informações jogadas nessas plataformas de pública visibilidade e acesso "acabam por diluir a concepção compartilhada sobre as fronteiras da privacidade de cada cidadão" (SARLET e FERREIRA NETO, 2019, p. 19), o que cria um impasse, próprio da contemporaneidade, entre dois direitos fundamentais e que, não raras as vezes demanda resposta, muitas vezes simbólica, do ordenamento jurídico para conferir à sociedade a sensação de segurança pelas mãos de uma lei.

É nesse contexto, de uma sociedade de hiperinformação, que se verifica o fenômeno do "não esquecimento" já que o ciberespaço possui uma memória digital, em total superação da memória analógica, pois se num passado recente as fotografias eram extraídas por meio de filmes e possuíam vida útil relativamente curta em função da forma e estado de conservação, hoje pelos dispositivos móveis é possível extrair uma gama de fotografias e armazená-las em servidor virtual como o "iCloud' e "Google Drive" entre outros, sem receio de perdê-las pelo estado de conservação.

O paradoxo decorrente do avanço tecnológico reside na facilidade de se fazer presente "sempre" na rede/ciberespaço/plataformas digitais e o rechaço quase que universal do direito à privacidade em nome de uma liberdade de expressão que vem assumindo a forma de um exibicionismo, pois para acessar os dados íntimos de uma pessoa física basta acessar

\footnotetext{
${ }^{10}$ Todo ser humano tem direito à liberdade de opinião e expressão; este direito inclui a liberdade de, sem interferência, ter opiniões e de procurar, receber e transmitir informações e ideias por quaisquer meios e independentemente de fronteiras
} 
seus perfis nas aplicações acima citadas, sendo que as ferramentas de bloqueio de informações muitas vezes são encaradas como tentativa de esconder algo dos demais usuários de determinada comunidade virtual.

É como se não houvesse mais comunhão entre os direitos fundamentais da liberdade de expressão e a privacidade, como se para estar presente no ecossistema digital, nosso avatar (que é uma extensão da nossa personalidade) precisasse abrir mão de um direito indisponível para gozar de outro.

Importante elucidar as palavras de Ingo Sarlet e Ferreira Neto (2019, p. 20),

Pois nesse novo ambiente hipercomunicativo, acaba-se criando um absoluto descontrole no manuseio, na armazenagem e no acesso dos dados pessoais que estão pulverizados na Internet, o que acaba fragmentando o nosso senso de privacidade e de personalidade, tornando-nos vulneráveis em relação ao que os demais pensam e falam sobre a nossa esfera individual e sobre nosso passado.

Assim, podemos entender a tecnologia como um organismo vivo e que se desenvolve porque se desenvolve, sem a necessidade de qualquer outra causa ou motivo. Se a sociedade da informação é regulada pelos avanços tecnológicos e esses são organismos vivos para além da compreensão do estado e do indivíduo, e se esses últimos respondem de forma defensiva ao medo do inadministrável, então por certo que nos depararemos com mecanismos que possam falsamente reestabelecer a sensação de estabilidade das organizações sociais.

\section{A EXTIMIDADE NA SOCIEDADE DA INFORMAÇÃO E A DEEPWEB}

Já se pontuou que a sociedade da informação pauta sua estrutura pelo maior número de dados em tempo inversamente proporcional onde a tecnologia possibilita uma maior publicização de informações, quer seja de caráter pessoal ou não, onde podemos entender que vivenciamos a era da extrospecção social e exibicionismo em detrimento da intimidade e privacidade.

Para analisar a garantia constitucional à privacidade, assim disposta no artigo $5 .^{\circ}$, inciso $\mathrm{X}^{11}$ da Carta Política onde "são invioláveis a intimidade, a vida privada, a honra e a imagem das pessoas, assegurado o direito a indenização pelo dano material ou moral

\footnotetext{
${ }^{11}$ Art. $5^{\circ}$ Todos são iguais perante a lei, sem distinção de qualquer natureza, garantindo-se aos brasileiros e aos estrangeiros residentes no País a inviolabilidade do direito à vida, à liberdade, à igualdade, à segurança e à propriedade, nos termos seguintes: (...) são invioláveis a intimidade, a vida privada, a honra e a imagem das pessoas, assegurado o direito a indenização pelo dano material ou moral decorrente de sua violação.
} 
decorrente de sua violação", é preciso reconhecer a transição de uma sociedade estática e sozinha em si, para uma sociedade dinâmica, líquida e totalmente ramificada por sistemas de comunicação (CASTELS, 2009, p. 57) ${ }^{12}$.

\subsection{A Internet como protagonista da extimidade em ecossistema digital}

A transição da sociedade moderna para a sociedade pós-moderna, como bem pontua Bauman (2007, p. 07), foi marcada pelo abandono da solidez de suas estruturas e certezas para um estágio líquido dos acontecimentos, onde tudo é mais volátil e instantâneo. A globalização, então, assume papel relevante nessa transição, pois tirou do indivíduo, enquanto ente coletivo, sua certeza de pertencimento e significação.

\subsubsection{A relativização do Direito Fundamental à privacidade no ciberespaço.}

A presença constante da tecnologia deu nova roupagem ao corpo social, pois fomos arrancados do pensamento estático para uma ótica instantânea, onde a informação nos permeia em uma velocidade que não compreendemos. Agora, o volume de informação ao nosso alcance exige que a sociedade esteja exposta e disposta à absorção de novas formas de interação.

Essa nova interação social implica em aceitar a exposição decorrente da sociedade da informação em razão do alto tráfego de dados, não raras as vezes tratados em ambiente digital por meio de dispositivos informáticos móveis ou aplicações de internet.

Ocorre que, na contramão do caráter robótico dessa estrutura social, contamos com o elemento humano, que outrora foi o protagonista da atividade social sendo agora destronado pela figura dos "dados". Elemento esse que está longe de compreender e acompanhar o dinamismo proposto pela tecnologia, tendo na sensação de medo, o seu refúgio.

$\mathrm{O}$ medo do incerto numa sociedade sem fronteiras antagoniza o anonimato e com isso se pretende dizer que a anonimização, por ir na contramão da sociedade da informação e da extimidade, é rotulada erroneamente e vinculada à ideia de que indivíduos que transitam pelo ciberespaço de forma anônima tem em si, obrigatoriamente, o propósito delitivo.

Nesse espectro está a sociedade da informação, pois a corrida para obtenção e monopólio da informação dita o ritmo de uma ou várias sociedades. A tecnologia e as várias formas de inteligência auxiliam essa busca. Então, tendo a sociedade da informação como

\footnotetext{
${ }^{12}$ As novas tecnologias da informação estão integrando o mundo em redes globais de instrumentalidade. A comunicação mediada por computadores gera uma gama enorme de comunidades virtuais.
} 
rede aberta, onde as tecnologias são utilizadas para acessar e captar cada vez mais e o maior número de informações, não há mais, num primeiro olhar, lugar para a privacidade ou garantia de intimidade.

O extermínio da privacidade parece decorrer dessa "revolução digital e ampliação do acesso a novas tecnologias", onde "passa-se a cultivar uma postura de revelação pública quase ilimitada de aspectos da vida privada de cada um, caracterizado como novo exibicionismo" (SARLET e FERREIRA NETO, 2019, p. 42).

Ocorre que a privacidade, antes de ser demonizada pela máxima "minha vida é um livro aberto", se trata de direito fundamental e, portanto, possui tutela constitucional, direito esse que assume novos contornos e que, na sociedade da hiperinformação, não raras vezes é mitigado em razão da intensidade e facilidade com que são transmitidas as informações pessoais (SARLET e FERREIRA NETO, 2019, p. 19). Ainda, a forma como nos relacionamos com a nossa memória foi completamente modificada, o que pelas mãos da internet, passamos a entender como "memória digital” (SARLET e FERREIRA NETO, 2019, p. 41).

O processo de globalização (ARNAUD, 2007, p. 21) ${ }^{13}$ sem sombra de dúvida implicou e implica ainda em discussões sobre a extensão do seu impacto nas relações sociais, jurídicas e econômicas.

No entender de Giddens (1990, p. 23), “a estrutura das instituições jurídicas modernas pressupõe altos graus de confiança, a qual tem sofrido um desgaste continuo desde os processos de industrialização do século XIX até o fenômeno da globalização e do multiculturalismo do mundo contemporâneo".

Para Arnaud (2007, p. 18), a sociedade para funcionar, necessita de referências. São estruturas reconhecidas pela comunidade internacional (as fronteiras, por exemplo) fornecidas pelas sociedades ou tecidas através dos laços sociais. Ocorre que as fronteiras, sejam geográficas ou sociais, são os primeiros alvos do aniquilamento global.

O efeito da globalização, em que pese tenha em seu escopo a aproximação e unificação, acentua a polarização social pela mutação fluente do capitalismo e a influência da regulação mercadológica, cada vez mais violenta, nas estruturas da soberania do Estado-

\footnotetext{
${ }^{13}$ Este processo, que consiste em transformar progressivamente o mundo inteiro em uma única região, traz perturbação ao espírito daqueles cuja missão é a de conduzir os negócios públicos de sua sociedade segundo uma regulação adaptada à sua história, a seus costumes e ás suas especificidades. (...) além da transgressão de fronteiras políticas, econômicas e financeiras, o conceito de globalização remete também à reorganização das fronteiras culturais. $\mathrm{O}$ que se entende mais comumente com isso, são as transformações sofridas pela cultura em sua relação com a "expansão do mercado capitalista mundial e seus modelos de produção e de consumo, o crescimento das formas e das redes de comunicações e o desenvolvimento das associações e dos movimentos políticos.
} 
nação. E na medida que o mercado assume novos contornos dignos de um "poder" vai enfraquecendo a legitimidade estatal, dando espaço a subversões legais e criando a cultura de “exclusão e inclusão".

Isso porque o mercado atua de forma global (CASTELS, 2009, p. 42) ${ }^{14}$ e competitiva (BAUMAN, 2009, p. 21) ${ }^{15}$, e os institutos estatais, que se retraem pelo dinamismo da economia e do mercado, atuam apenas de forma local não conseguindo ter sequer ingerência nos conflitos de ordem global, ou seja, acabam sendo insuficientes para realizar e efetivar os direitos democraticamente consagrados.

Com isso se pretende dizer que o Estado, muito mais do que palco das relações comerciais, deve fortalecer seu caráter social, esvaziando assim os espaços em que o ordenamento jurídico é chamado a promover segurança social já que o processo de globalização é uma constante e já permeou as diversas camadas do Estado Democrático Constitucional de Direito.

3.1.2 A (in)segurança do indivíduo na navegação em ambiente com indexação de dados

Com intuito de facilitar a compreensão do leitor, o termo "navegação" aqui será utilizado para identificar o acesso de usuários na Internet e “indexação de dados” para qualificar a escolha do usuário pela Internet aberta ou "surface" onde o acesso deixa rastros e atrela ao acesso do usuário seu histórico de acessos, pesquisas, transações, conteúdo de pesquisas sob a forma de dados.

Em termos objetivos, a Internet é a prova da comunicação em rede e que se auto reproduz já que é "composta por uma extensa infraestrutura que abriga redes interligadas entre $\mathrm{si}$ - obedecendo, para isso uma linguagem de envio e recebimento de dados, o protocolo TCP/IP. " (CALDERON, 2017, p. 157).

Em termo técnicos, a estrutura ramificada da Internet se baseia em criação de algoritmos ${ }^{16}$ e programação sendo um grande exemplo o mecanismo de busca e pesquisa do

\footnotetext{
${ }^{14}$ Contudo, podemos afirmar que existe uma economia global, porque as economias de todo o mundo dependem do de- empenho de seu núcleo globalizado. Esse núcleo globalizado contém os mercados financeiros, o comércio internacional, a produção transnacional e, até certo ponto, ciência e tecnologia, e mão-de-obra especializada. É por intermédio desses componentes estratégicos globalizados da economia que o sistema econômico se interliga globalmente.

${ }^{15}$ Quando a solidariedade é substituída pela competição, os indivíduos se sentem abandonados a si mesmos, entregues a seus próprios recursos - escassos e claramente inadequados. A corrosão e a dissolução dos laços comunitários nos transformaram, sem pedir nossa aprovação, em indivíduos de jure (de direito); mas circunstâncias opressivas e persistentes dificultam que alcancemos o status implícito de indivíduos de facto (de fato).

${ }^{16} \mathrm{O}$ termo algoritmo vem da palavra árabe alkharizimi, originária do nome de um matemático peras chamado Abu Já'far Mohammed Ibn Musa al Khowarizimi, autor de um livro-texto sobre matemática no século IX. Em português, a palavra quer dizer "operação ou processo de
} 
Google que, por meio de algoritmos armazena a busca dos usuários e as deposita em seu banco de dados para alimentá-lo e para atrelar a pesquisa ao usuário, criando assim seu perfil para possibilitar inclusive uma análise preditiva ${ }^{17}$ do acesso, escolhas, preferências, transações e sites visitados, definindo cada vez mais o padrão de condutas adotadas pelo usuário.. .

Ocorre que esse acesso registrado, catalogado e armazenado e que possibilita a construção do perfil fidedigno do usuário se dá apenas na Internet aberta ou surface já que essa interface da "World Wide Web" dispõe de mecanismos ajustados para recepcionar ferramentas de busca e armazenamento de dados com alta rastreabilidade.

Ainda, dados lançados na Internet, principalmente na surface não são excluídos por uma impossibilidade algorítmica e estrutural, mas podem ser desindexados, considerando que a navegação nesse ambiente não permite navegação anônima, mantendo incólume a memória digital do usuário, mesmo que esse deseje o contrário, excetuada as situações judicializadas para acionar o direito ao esquecimento, onde efetivamente, por determinação judicial deve haver a desindexação dos dados do usuário para o caso de buscas de seus nome e outras informação à aquele correlatas na Internet.

Entretanto, o outro lado da moeda é que, "a Internet transformou as relações sociais. Assim como na ficção de Hitchcock, vive-se o voyeurismo, desfruta-se a exposição, porém enquanto alguns se expõem outros observam”. (WENDT e MEINERO, 2018, p. 638). Mais, experimentando essa extimidade digital, os usuários invariavelmente e inevitavelmente estão sujeitos à persuasão e, não raras as vezes à manipulação das forças mercadológicas que, também possuem atuação no ciberespaço.

Diante de toda extimidade do cenário digital que exige a indexação de nossos dados, mesmo que tenhamos a proteção constitucional de nossa privacidade, fato é que estamos expostos a olhares alheios e somos diariamente vigiados pelos provedores, sites de busca, redes sociais, sites governamentais e é claro pela atividade de hackers, que não raras as vezes aplicam em nossos dispositivos, conteúdo malicioso com fim ilícito.

cálculo". De uma maneira geral, o termo algoritmo evoca a noção de um processo para resolver um problema. Obviamente, a razão de ser do algoritmo vem da essência de uma dissonância entre um estado desejado e aquele observado na realidade. Um algoritmo é uma sequência ordenada finita de operações bem definidas e eficazes que, quando executadas por um computador, operando sobre dados caracterizando o estado atual do contexto e o estado desejado, sempre termina num determinado período de tempo, produzindo uma solução ou indicando que a solução não pode ser obtida. SWAIT JR., Joffre Dan. Fundamentos computacionais. Algoritmos e estruturas de dados. São Paulo: Editora Makron.1991. p. 03-04.-

17 Análises preditivas usam dados, algoritmos estatísticos e técnicas de machine learning para identificar a probabilidade de resultados futuros, a partir de dados históricos. O objetivo é ir além de saber o que aconteceu para obter uma melhor avaliação do que poderá acontecer no futuro. A análise preditiva é exatamente a junção do avanço tecnológico que temos, que inclui mineração de dados, machine learning, inteligência artificial e estatística, com o alto volume de informações que criamos diariamente. Quando usamos computadores para processar e entender comportamentos padrões, conseguimos antecipar certos acontecimentos e ações. 
Nesse contexto, é a rede que causa insegurança ou o proceder do elemento humano? Dúvida essa que não altera a seguinte informação: mesmo que com sentimento de insegurança, as pessoas seguirão acessando a Internet, pois mesmo com as fragilidades e lacunas técnicas da Internet a vontade do desvio não está no algoritmo e sim no elemento humano. O medo não impede e não impedirá o acesso e se o contrário fosse, esse trabalho sequer poderia ser enviado por e-mail.

Essa necessidade de se reestabelecer a segurança decorre do medo derivado das experiências humanas alheias e que, por entendermos ser quase impossível sua superação, nos tornamos vulneráveis à essa subjetividade que, muitas vezes sequer se concretiza, mas que nos insere numa realidade potencialmente perigosa e contra a qual somente instrumento de controle social pode dar resposta à autopropulsão desse sentir.

O medo derivado, então, pode residir também na surface, local onde estamos muito mais expostos e de onde se extrai também prática delitiva, sendo que na "DeepWeb" também encontramos vasto conteúdo lícito (CALDERON, 2017, p. 127-129), já que estudos apontam que a internet profunda é 500 vezes maior que a internet superficial (CALDERON, 2017, p. 08).

De tudo que foi trazido e argumentado, se pode extrair um pequeno indício de fechamento, pois posições estáticas não cabem num cenário em movimento como a Internet, seja ela aberta ou não e, nesse sentido, por mais atraente que seja o ambiente da surface a insegurança reside muito mais no elemento humano do que nas portas lógicas e estrutura da rede. Insegurança essa decorrente de uma fragilidade a nós imposta pelas mãos da globalização, precarização do Estado Social, e grau de exposição que, hoje parece ter se tornado condição de acesso e interação na surface.

Por fim, navegar em mares abertos, sem o GPS atualizado amplia a possibilidade de extraviar o caminho e o objetivo a ser seguido, mas há os que prefiram navegar sem registros e rumo, primando apenas pela privacidade e anonimato.

\subsection{O uso da DeepWeb na contramão do exibicionismo digital}

Como anteriormente dito, a surface, por sua estrutura, não admite o anonimato de seus usuários, havendo um acordo tácito quanto à coleta e armazenamento de seus dados. Se de um lado os usuários têm a liberdade e as ferramentas para publicar e compartilhar suas 
informações na internet aberta, do outro, essas informações serão desindexadas somente com intervenção judicial.

Em contrapartida, existem usuários que, na tentativa de resguardar sua privacidade e conteúdo de seus acessos, adotam o anonimato em sua navegação, já que optam por transitar na Internet profunda, ou DeepWeb ${ }^{18}$, que pode ser entendida por uma camada da rede onde, por meio de softwares livres se acessam páginas, fóruns, conteúdo literário e se realizam transações por meio de criptografia com baixa rastreabilidade já que não conta com algoritmo para indexação de dados. Importante dizer que a criptografia também é utilizada na surface, mas na DeepWeb é elemento indissociável de sua estrutura.

\subsubsection{A "Internet profunda" para além do estigma conferido aos seus usuários}

Algumas características dessas duas camadas da rede, então, devem ser explicitadas no presente trabalho, pois a surface é acessada por navegadores como Microsoft Edge (Microsoft); Google Chrome (Google); Mozila Firefox (Mozilla Foundation) etc. Já a DeepWeb só pode ser acessada por navegadores como Tor; Ip2; Freenet; possuindo também versões menos populares como Dot-P2P; Phanton; Globaleaks etc.

O navegador Tor é o mais comumente utilizado pela forte criptografia empregada, tendo a capacidade de anonimizar, quase que por completo, o usuário. A internet profunda teve extensa utilização para fins militares e hoje é utilizada também para manifestações políticas, sociais e fins jornalísticos, pois como se indicou acima, a DeepWeb, por ser maior do que a surface, é depositário de uma gama de obras disponíveis gratuitamente aos usuários.

Muito da interface má que a DeepWeb carrega decorre de momentos históricos como “Silk Road ${ }^{19 ” ; ~ “ w i k i l e a k s ~}{ }^{20 "}$ que possui site na Internet aberta - https://wikileaks.org/ - sendo

\footnotetext{
${ }^{18}$ A deep web surgiu graças ao Laboratório de Pesquisas da Marinha dos Estados Unidos, que criou o The Onion Routing, um sistema de comunicações secreto que seria responsável por enviar dados e análises de sistemas através da internet anonimamente. No entanto, em 2006 , foi lançada uma versão do projeto para fins não-governamentais, intitulada de TOR (sigla de The Onion Routing). A palavra "onion" significa "cebola", em português, fazendo alusão às várias camadas que existem na cebola, semelhantes às camadas que um internauta deve atravessar para chegar ao conteúdo desejado em algum site da deep web. O FBI, Federal Bureau of Investigation ("Agência Federal de Investigação", em português), une esforços com outras instituições para vigiar a deep web, tentando capturar criminosos ou solucionar crimes que são expostos nos fóruns da "internet invisível". https://www.significados.com.br/deep-web/ em 20.12.2019. Mike Bergman, fundador da Bright Planet e autor da expressão "deep web”, afirmou que a busca na internet pode ser comparada com o arrastar de uma rede na superfície do oceano: pode-se pescar um peixe grande, mas há uma grande quantidade de informação que está no fundo, e, portando faltando. https://hackersec.com/conheca-mais-de-100-sites-que-voce-pode-acessar-na-deep-web/. Em 20.12.2019.

${ }^{19}$ A dark web apareceu mesmo para o público geral em 2011, ano de fundação da norte-americana Silk Road, uma plataforma na deep web de venda de drogas, remédios de uso controlado e até produtos legalizados, como livros. O nome vem da Rota da Seda, as estradas comerciais do século 9 para ligar Europa e Ásia no comércio de mercadorias. A plataforma começou limitada, com poucos vendedores e regras rígidas do que podia por lá. O líder tinha o apelido de Dread Pirate Roberts, um personagem do excelente filme "A Princesa Prometida", que lutava por ideais libertários e não gostava de autoridades. Só que logo a mídia começou a fazer matérias sobre a loja, e isso chamou a atenção de políticos e autoridades dos Estados Unidos. Em 2013, Ross Ulbricht foi preso e condenado à prisão perpétua por ser o fundador do site, mas ele negou que era o atual Dread Pirate Roberts. https://www.tecmundo.com.br/internet/131843-historia-deep-websubmundo-da-internet-video.htm. Em 20.12.2019
} 
a coleta e troca de dados feitas pela DeepWeb; Anonymous e casos de pornografia infantil e pedofilia. É claro que o anonimato facilita o desvio ${ }^{21}$, mas não o constitui e nem mesmo o condiciona. Tanto é que os delitos praticados por meio da Internet profunda não raras as vezes também são praticados na surface. Assim, parece descabido o estigma ${ }^{22}$ generalizado que carregam os usuários que optam pela privacidade de e na sua navegação, mesmo que estejamos diante da máxima da extimidade social como regra aparente da sociedade da informação.

Ainda, o ambiente sem indexação de dados não pode receber o rótulo de mau ou facilitador de delitos, já que o ato desviante é uma construção social e não do indivíduo ${ }^{23}$, onde por mais que o anonimato seja encarado como lógica disruptiva do jogo social, o usuário da DeepWeb não pode ser visto como "outsider". ${ }^{24}$

3.2.2 Abordando o medo e o perigo na "Internet profunda": breve análise do caso de Suzano-SP

Por fim, nesse cenário, contextualizamos o caso prático da presente pesquisa, pois em 13 de março de 2019, na cidade de Suzano, São Paulo, dois jovens (um de 17 e outro de 25 anos) planejaram e executaram delito em massa, causando 10 mortes e deixando outros 10 feridos, onde as investigações apontam que os autores do delito teriam utilizado fóruns e chans existentes na "DeepWeb" para obter tutorial do delito chamado "School Shooting", trazendo as atenções midiáticas para essa nuance da rede de forma a associar seu uso e seus usuários à potencial fomento para prática de crimes.

Como antes dito, ojerizamos o que não entendemos e, por essa razão, e justamente para afastar discursos de ódio e de marginalização social, é que Francisco Brito Cruz, em

\footnotetext{
${ }^{20}$ WikiLeaks é uma organização transnacional sem fins lucrativos, sediada na Suécia, que publica, em sua página, postagens de fontes anônimas, documentos, fotos e informações confidenciais, vazadas de governos ou empresas, sobre assuntos sensíveis. A página foi construída com base em vários pacotes de programas (software), incluindo MediaWiki, Freenet, Tor e PGP. Apesar do seu nome, a WikiLeaks não é uma wiki - leitores que não têm as permissões adequadas não podem editar o seu conteúdo. A página, administrada por The Sunshine Press, foi lançada em dezembro de 2006 e, em meados de novembro de 2007, já continha 1,2 milhão de documentos. Seu principal editor e porta-voz é o australiano Julian Assange, jornalista e ciberativista. https://pt.wikipedia.org/wiki/WikiLeaks. Em 20.12.2019 ${ }^{21}$ A concepção sociológica que acabo de discutir define desvio como infração de alguma regra geralmente aceita. Ela passa então a perguntar quem infringe regras e a procurar os fatores nas personalidades e situações de vida dessas pessoas, e que poderiam explicar infrações. BECKER, Howard S. Outsiders. Estudos de sociologia do desvio. Tradução Maria Luiza X. de Borges. Rio de Janeiro: Zahar, $2008 . p .18$.

${ }^{22}$ Situação do indivíduo que está inabilitado para a aceitação social plena. Um estigma é, então, na realidade, um tipo especial de relação entre o atributo e o estereótipo. GOFFMAN, Erving. Estigma. Notas sobre a manipulação da identidade deteriorada. Tradução Marcia Bandeira de Mello Leite Nunes. Rio de Janeiro: LTC, 2013.p. 07 e 13.

${ }^{23}$ (..) tal pressuposto parece-me ignorar o fato central acerca do desvio: ele é criado pela sociedade. Não digo isso no sentido em que é comumente compreendido, de que as causas do desvio estão localizadas na situação social de desviante ou fatores sociais que incitam sua ação. Quero dizer, isto sim, que grupos sociais criam o desvio ao fazer as regras cuja infração constitui desvio, e ao aplicar essas regras a pessoas particulares e rotulá-las como outsiders. BECKER, Howard S. Outsiders. Estudos de sociologia do desvio. Tradução Maria Luiza X. de Borges. Rio de Janeiro: Zahar, 2008.p. 21-22.

${ }^{24} \mathrm{O}$ outsider - aquele que desvia as regras do grupo. BECKER, Howard S. Outsiders. Estudos de sociologia do desvio. Tradução Maria Luiza X. de Borges. Rio de Janeiro: Zahar, 2008.p
} 
entrevista concedida ao site "Huffpost" em 15 de março de 2019, destaca que, apesar de ser um espaço que proporciona esse tipo de organização e de crimes, a deep web não é ilegal. Inclusive, o navegador Tor foi financiado por muito tempo pelo próprio governo dos Estados Unidos. Prossegue seu posicionamento argumentando que, a ferramenta de ocultamento de identidade é importante, sobretudo, em casos de conflitos políticos e investigações delicadas: da mesma forma que a criptografia protege a mensagem, esse tipo de ferramenta protege o emissor da mensagem.

Ainda, enfatiza o rechaço ao discurso de ódio sob o argumento que esse precede à "DeepWeb", sendo a violência um fenômeno maior que a internet profunda, onde os fóruns ou chans são mais um dos espaços encontrados por essa cultura online que já ocupa vários espaços e que está em constante migração. Ou seja: o discurso de ódio está além da própria deep web. Finaliza seu parecer indicando que precisamos evitar a explicação tecnocêntrica de atentados como o de Suzano. Apesar da existência desses fóruns e de sua possível influência nos ataques, esse argumento é simplista.

Assim, se a internet é a mola propulsora da derrubada das nossas fronteiras geográficas e de segurança, como não demonizar a "DeepWeb", já que se afasta do fluxo em que somos arremessados diariamente, onde o senso comum, que pouco sabe das nuances da "World Wide Web", sequer consegue diferenciar internet profunda da "DarkWeb" (CALDERON, 2017, p. 11).

\section{CONSIDERAÇÕES FINAIS}

$\mathrm{O}$ apanhado sociológico promovido por Anthony Giddens aportou à pesquisa as consequências da modernidade no desenvolvimento e constância das relações sociais e de que forma essas relações lidam com a transição do caráter estático desse período para o dinamismo inerente também à globalização.

Nesse ínterim, o trabalhou, em linhas gerais, teve por objetivo pontuar os efeitos da globalização nas estruturas sociais, evidenciando o despreparo do indivíduo e Estado para a percepção e vivência de um cenário fluído e que se desenvolve e ramifica aceleradamente.

Conectou-se velocidade à fluidez também em função da queda das fronteiras geográficas e sociais promovidas pela globalização, inclusive pelas mãos da Internet, que atenuou consideravelmente a noção de tempo e espaço, possibilitando a criação e proliferação de um novo cenário social, também conhecido como sociedade da informação. 
Nesse contexto, a Internet assumiu o papel de organismo vivo e que nos proporciona o maior número de informação e um tempo exíguo, onde a pesquisa se restringiu apenas à dicotomia evidente entre a "surface" e a "DeepWeb" para verificar a conduta e sensação humana frente a camada profunda da rede.

A pesquisa aqui intentada, ainda possibilitou concluir que, assim como a "surface", a internet profunda é uma realidade global e que é inerente à sociedade da informação e nossa incapacidade de transpirar os resultados da modernidade tardia, não pode ser o substrato do medo e justificativa para ressignificação do perigo quando da navegação em ambiente sem indexação e dados.

A tutela da privacidade na sociedade da informação tem como objetivo a realização integral do ser humano de forma digna, já que o conteúdo exposto no ciberespaço é uma extensão da nossa personalidade nessa releitura e contexto cibersocial.

Assim, o presente trabalho avaliou que, a escolha por navegação sem indexação de dados, a qual somente e possível na "DeepWeb", não pode ser vista como transgressão, já que a privacidade possui amparo constitucional e esse ecossistema digital não inflige perigo ou medo simplesmente por existir e ser avesso à extrospecção social, não devendo haver tutela penal para seu uso e acesso, sob pena de agravamento ao expansionismo legiferante, não raras as vezes de cunho apenas simbólico.

\section{REFERÊNCIAS}

ARNAUD, André-Jean. Governar sem fronteiras. Entre globalização e pós-globalização. Crítica da razão jurídica. Vol. 2. Rio de Janeiro: Lumen Juris, 2007.

BAUMAN, Zygmunt. Confiança e medo na cidade. Tradução Eliana Aguiar. Rio de Janeiro: Zahar, 2009.

BAUMAN, Zygmunt. Tempos Líquidos. Tradução Carlos Alberto Medeiros. Rio de Janeiro: Zahar, 2007.

BAUMAN, Zygmunt. Medo Líquido. Tradução Carlos Alberto Medeiros. Rio de Janeiro: Zahar, 2008,

BECK, Ulrich. Sociedade de risco: rumo a outra modernidade. Tradução Sebastião nascimento. São Paulo: Editora 34.2010.

BECKER, Howard S. Outsiders. Estudos de sociologia do desvio. Tradução Maria Luiza X. de Borges. Rio de Janeiro: Zahar, 2008.

BRASIL. Constituição (1988). Constituição da República Federativa do Brasil. Brasília, DF: Senado Federal: Centro Gráfico, 1988.

CALDERON, Bárbara. Deep e Dark Web. Rio de Janeiro: Alta Books, 2017.

CASTELS, Manuel. Sociedade em Rede. São Paulo: Editora Paz e Terra, 2009. 
DA COSTA, Renata Almeida de. A sociedade complexa e o crime organizado: A contemporaneidade e o risco nas organizações Criminosas. Editora Rio de Janeiro: Lumen Juris. 2004.

DE GIORGI, Rafaelle. Direito, democracia e risco. Vínculos com o futuro. Porto Alegre: Sergio Antônio Fabris Editor. 1998

GIDDENS, Anthony. As consequências da Modernidade. Tradução de Raul Filker. São Paulo: Unesp, 1990.

GIDDENS, Anthony. A constituição da sociedade. Tradução de Álvaro Cabral. São Paulo: editora WMF Martins Fontes, 2009.

GIDDENS, Anthony. Modernidade e identidade. Tradução de Plínio Dentzien. Rio de Janeiro: Zahar, 2002.

GOFFMAN, Erving. Estigma. Notas sobre a manipulação da identidade deteriorada. Tradução Marcia Bandeira de Mello Leite Nunes. Rio de Janeiro: LTC, 2013.

HALL, Stuart. A identidade cultural na pós-modernidade. Tradução Tomaz Tadeu da Silva. Rio de Janeiro: DP\& A, 2005.

KRETSCHMANN, Ângela, WENDT, Emerson. Tecnologia da Informação \& Direito. Porto Alegre: Livraria do Advogado, 2018.

ROCHA, Leonel Severo, SCHWARTZ, Germano, CLAM, Jean. Introdução à teoria do sistema autopoiético do Direito. 2. ed. rev. e ampl. Porto Alegre: Editora Livraria do Advogado. 2013.

ROSA, Ana Beatriz. Deep web e chans: envolvimento de assassinos de Suzano na internet é investigado. HuffPost, 2019. Disponível em: <https://www.huffpostbrasil.com/entry/deepweb-suzano-assassinos-dogolachan_br_5c8abd51e4b0db7da9f0fd20>. Acesso em: 15 de out. de 2019.

SARLET, Ingo Wolfgang, FERREIRA NETO, Arthur M. O Direito ao esquecimento na sociedade da informação. Porto Alegre: Livraria do Advogado, 2019.

SCHWARTZ, Germano. O tratamento jurídico do risco no direito à saúde. Porto Alegre. Livraria do Advogado: 2004.

SWAIT JR., Joffre Dan. Fundamentos computacionais. Algoritmos e estruturas de dados. São Paulo: Editora Makron.1991.

WENDT, Emerson. Internet \& Direito Penal: risco e cultura do medo. Porto Alegre:

Livraria do Advogado, 2017.

WENDT, Emerson. Internet: Percepções e Limites em face do Direito à Extimidade na Rede. Revista Jurídica Luso Brasileira, v.6, 2015.

WENDT, Emerson MEINERO, Fernanda Sartor. Janela Indiscreta e a Deep Web: O Olhar Do Estado Pela Lente Do Direito. Revista Jurídica Luso Brasileira, Ano 4, nº 4, 2018.

WENDT, Emerson. Direito \& TI: cibercrimes. Porto Alegre: Livraria do Advogado, 2019. 